\title{
Prevalence, risk and genetic characteristics of drug-resistant tuberculosis in a tertiary care tuberculosis hospital in China
}

This article was published in the following Dove Press journal:

Infection and Drug Resistance

\author{
Li-Li Zhaol,* \\ Ming-Xiang Huang ${ }^{2} *$ \\ Tong-Yang Xiao' \\ Hai-Can Liu' \\ Ma-Chao $\mathrm{Li}^{\prime}$ \\ Xiu-Qin Zhao' \\ Zhi-Guang Liu' \\ Yi Jiang' \\ Kang-Lin Wan'
}

'State Key Laboratory for Infectious Disease Prevention and Control, Collaborative Innovation Center for Diagnosis and Treatment of Infectious Diseases, National Institute for Communicable Disease Control and Prevention, Chinese Center for Disease Control and Prevention, Beijing 102206, People's Republic of China; ${ }^{2}$ Clinical Laboratory, Fuzhou Pulmonary Hospital, Fuzhou, 350008, People's Republic of China

*These authors contributed equally to this work

\begin{abstract}
Objectives: To explore the prevalence, risk and genetic characteristics of drug-resistant tuberculosis (TB) from a tertiary care TB hospital in China.

Patients and methods: We carried out a retrospective study including isolates from 189 patients with pulmonary TB at Fuzhou Pulmonary Hospital. All isolates from these patients were subjected to drug susceptibility testing and genotyping. For drug-resistant isolates, DNA sequencing was used to investigate mutations in 12 loci, including $k a t G$, inh $A$, oxyRahpC, rpoB, rpsL, rrs $s_{1}$ (nucleotides 388-1084 of rrs), embB, tlyA, eis, $r r s_{2}$ (nucleotides 1158-1674 of rrs), gyrA and gyrB.
\end{abstract}

Results: Among 189 isolates, $28.6 \%$ were resistant to at least one of the seven anti-TB drugs, including isoniazid (INH), rifampin (RIF), streptomycin (STR), ethambutol (EMB), capreomycin (CAP), kanzmycin (KAN) and ofloxacin (OFX). The proportion of multidrugresistant TB and extensively drug-resistant $\mathrm{TB}$ isolates was $9.5 \%$ and $1.1 \%$, respectively. Patients in rural areas as well as previously treated patients showed a significantly increased risk of developing drug resistance. In addition, among these isolates, 111 (58.7\%) were Beijing genotype strains, 84 (75.7\%) of which belonged to modern Beijing sublineage. There was no association between genotype and drug resistance. The most common mutations were katG315, rpoB531 rpsL43, embB306, rrs1401 and gyrA94.

Conclusion: These findings provided additional information of drug-resistant TB in China. Previously treated patients and patients in rural areas should receive greater attention owing to their higher risk of developing drug resistance.

Keywords: drug-resistant tuberculosis, genotype, risk, mutation

\section{Introduction}

Tuberculosis (TB) remains a major threat to public health in China, with an incidence around 100 cases per 100,000 population per year. ${ }^{1}$ It is the second leading cause of death from infectious diseases. Although TB incidence had decreased substantially in recent years after implementation of the DOTS strategy, the emergence of drug-resistant TB, especially multidrug-resistant TB (MDR-TB) and extensively drug-resistant TB (XDR-TB) have severely hampered TB control. According to the latest national survey on drug-resistant $\mathrm{TB}$ in $\mathrm{China},{ }^{2}$ the proportions of drug-resistant TB, MDR-TB and XDR-TB were $38.25 \%, 8.32 \%$ and $0.68 \%$, respectively.

Drug resistant-TB can occur when appropriate anti-TB medications are used incorrectly in both the public health and hospital systems. Treatment of drug-resistant
Correspondence: Kang-Lin Wan State Key Laboratory for Infectious Disease Prevention and Control, Collaborative Innovation Center for

Diseases, National Institute for Communicable Disease Control and Prevention, Chinese Center for Disease Control and Prevention, P.O. Box 5 Changping, Beijing 102206, People's Republic of China

$\mathrm{Tel} / \mathrm{Fax}+861058900779$

Email wankanglin@icdc.cn 
TB requires more expensive anti-TB drugs and longer therapy, factors that are responsible for most of the TB burden. Knowledge of the epidemic and genetic characteristics of drug-resistant TB will facilitate their effective management. However, prior data suggest that such information demonstrates large geographically related differences. ${ }^{3-7}$

It is well known that previously treated patients have a higher risk of developing drug resistance, thus representing an important source of drug-resistant disease transmission. ${ }^{8,9}$ Considering the higher rates of retreatment and refractory TB cases in specialized hospitals, it is necessary to investigate the epidemiological profile of drug-resistant TB in the hospital, to improve TB control.

In this study, we explored the drug-resistance profiles and risks associated with TB isolates collected in Fuzhou Pulmonary Hospital, the largest and sole tertiary care TB hospital in Fujian Province, China. Among drug-resistant isolates, we also analyzed the genotype and mutation characteristics of hot spot regions within 12 genetic loci including $k a t G$, inhA and $o x y R-a h p C$ (for resistance to $\mathrm{INH}$, $r p o B$ (RIF), $r p s L$ and $r r s_{1}$ (SM), embB (EMB), $\operatorname{tly} A$ (CAP), eis (KAN), $r s_{2}$ (CAP and KAN), and gyrA and $\operatorname{gyr} B(\mathrm{OFX})$.

\section{Methods}

\section{Ethical approval}

This study was conducted in accordance with guidelines of the Declaration of Helsinki and was approval by the Ethics Committee of National Institute for Communicable Disease Control and Prevention, Chinese Center for Disease Control and Prevention. Patients with TB were included in this research only after we received written informed consent from the patient or from their parent/ guardian in patients less than 18 years of age.

\section{Study population}

This study was carried out from September to December, 2009 at the Fuzhou Pulmonary Hospital, located in the capital of Fujian Province, which is the largest specialized TB hospital in Fujian Province. During this period, all patients with clinically suspected pulmonary TB were included.

\section{Bacteriological procedures}

A sputum sample from each patient was examined for acidfast bacilli (AFB) using standard Ziehl-Neelsen staining and then cultured on BACTEC MGIT 960 system. For positive cultures, the $P$-nitrobenzoic acid inhibition test was used to differentiate Mycobacterium tuberculosis complex (MTC) from non-tuberculous Mycobacteria (NTM).

For MTC strains, drug susceptibility testing (DST) was performed using the Lowenstein-Jensen (L-J) proportion method (PM). ${ }^{10}$ Critical concentrations in DST were $0.2 \mu \mathrm{g} / \mathrm{mL}$ for INH, $40.0 \mu \mathrm{g} / \mathrm{mL}$ for RIF, $4.0 \mu \mathrm{g} / \mathrm{mL}$ for $\mathrm{SM}, 2.0 \mu \mathrm{g} / \mathrm{mL}$ for EMB, $40 \mu \mathrm{g} / \mathrm{mL}$ for CAP, $30 \mu \mathrm{g} / \mathrm{mL}$ for $\mathrm{KAN}$ and $2.0 \mu \mathrm{g} / \mathrm{mL}$ for OFX, respectively. Quality control was routinely performed during DST using the reference strain H37Rv (ATCC 27294).

\section{Data collection and definition}

Demographic and clinical information of enrolled patients was obtained from the patient's records including sex, age, address, complications and TB treatment history.

Migrants were defined as individuals from other provinces of China who had moved to Fujian. Residents were defined as individuals with a registered permanent residence in Fujian. New or previously treated TB cases were defined as previously described. ${ }^{11}$

\section{DNA extraction and genotyping}

Genomic DNA was prepared using the CTAB method as described by Somerville et al. ${ }^{12}$ Strain differentiation was performed with spoligotyping as described by Kamerbeek et al. ${ }^{13}$ Further genotyping of Beijing family strains was done according to the presence or absence of IS6110 in the noise transfer function (NTF) region as described previously. ${ }^{14,15}$ Modern Beijing strains inserted in the NTF region yielded $1500 \mathrm{bp}$ PCR products, while ancient Beijing strains without insertions yielded 300 bp PCR products.

\section{PCR amplification and sequencing}

The expected fragments were amplified using the primers and conditions described in our previous study., ${ }^{7,9}$ PCR products were sent for DNA sequencing. All sequences were aligned with the homologous sequences of the reference strain $\mathrm{H} 37 \mathrm{Rv}$ (GenBank accession number NC_000962) using BioEdit software version 7.05.3.

\section{Statistical analysis}

Statistical analysis of drug resistance and risk factors was performed with SPSS version 16.0 (SPSS Inc., Chicago, IL, USA). Chi-square test or Fisher's exact probability test was used to compare the proportions of different groups. Differences were considered statistically significant with $\mathrm{P}<0.05$. 


\section{Results}

\section{Demographic information}

In this study, a total of 330 patients with clinically suspected pulmonary TB were included. Of them, 61 (18.5\%) patients had a positive acid-fast bacilli smear, and $202(61.2 \%)$ patients had positive cultures. Nevertheless, among 202 culture-positive cases, 189 were identified as MTC whereas the remaining 13 were NTM. Thus, 189 patients with MTC were formally enrolled in this study and underwent further anti-TB DST. Of these patients, $132(69.8 \%)$ were male and 57 (30.2\%) were female. The mean age was 40.4 years (range: $14-85$ years). Most patients (88.9\%, 168/189) were Fujian residents and $84.7 \%(160 / 189)$ were newly diagnosed cases.

\section{Drug susceptibility patterns}

DST results against the seven anti-TB drugs indicated that among 189 isolates, 54 (28.6\%; 95\% CI, 22.1-35.0\%) isolates were resistant to at least one drug. A total 42 isolates $(22.2 \%$; 95\% CI, 16.3-28.2\%) were resistant to INH, 19 (10.1\%; 95\% CI, 5.8-14.3\%) to RIF, 31 (16.4\%; 95\% CI, $11.1-21.7 \%)$ to SM, 6 (3.2\%; 95\% CI, $0.7-5.8 \%)$ to EMB, 2 (1.1\%) to CAP, 2 $(1.1 \%)$ to KAN and $10(5.3 \%$; $95 \%$ CI, $2.1-8.5 \%)$ to OFX. Overall 18 isolates $(9.5 \% ; 95 \%$ CI, 5.3-13.7\%) were identified as MDR-TB, including 6 pre-XDR TB (3.2\%) and 2 XDR-TB
(1.1\%) isolates (Figure 1). The proportions of drug-resistant TB among new cases and previously treated cases were also shown in Table 1. Most MDR-TB (66.7\%, $12 / 18$ isolates), preXDR TB (83.3\%, 5/6 isolates) and XDR-TB (100.0\%, 2/2 isolates) were from previously treated patients.

\section{Genotype results}

Of 189 TB isolates, 111 (58.7\%) belonged to the Beijing family, whereas the other $78(41.3 \%)$ belonged to nonBeijing family, including $\mathrm{T}$ (36 isolates, $19.0 \%$ ), H (15 isolates, 7.9\%), U (4 isolates, 2.1\%), MANU2 (3 isolates, $1.6 \%$ ), EAI (1 isolate, $0.5 \%$ ), and orphan (19 isolates, $10.1 \%$ ). A further approximate subdivision of Beijing family strains was performed according to the presence of IS6110 in the NTF region. The results showed that $75.7 \%$ (84 isolates) of Beijing strains had an IS6110 insertion in the NTF region and were thus classified in the modern Beijing subgroup.

\section{Risk factors for drug-resistant TB}

Table 2 showed analysis of the risk factors for MDR and drug-resistant (but not MDR) TB among the 189 patients. Previously treated patients showed a markedly increased risk for developing drug resistance (but not MDR) and developing MDR, with OR values of 5.29 (95\% CI, 1.87-14.96; $P=0.00)$ and $6.00 \quad(95 \% \quad \mathrm{CI}, \quad 1.74-20.67 ; \quad P=0.00)$,

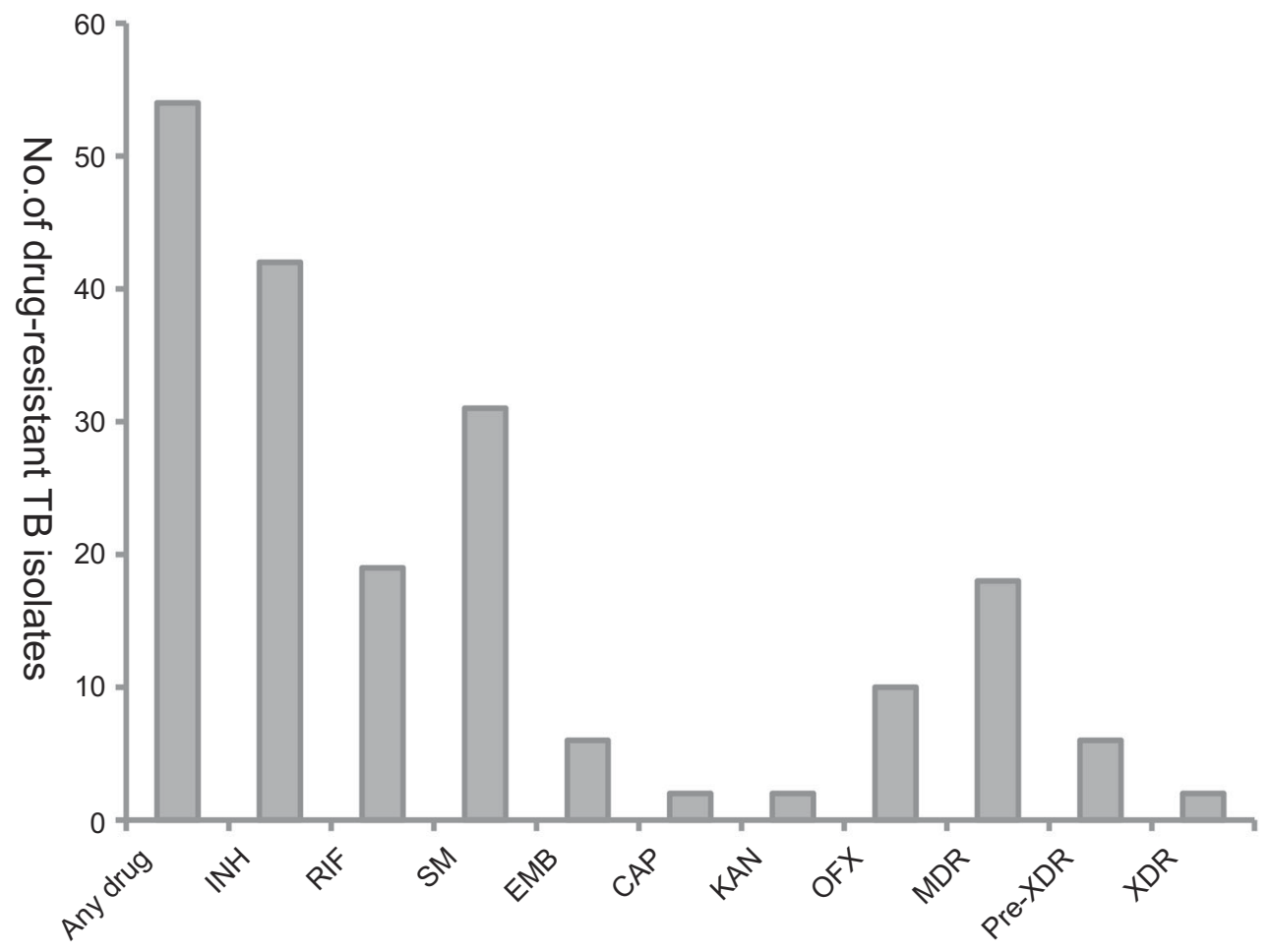

Figure I The drug-resistant TB in a tertiary care tuberculosis hospital from China.

Abbreviations: INH, isoniazid; RIF, rifampin; STR, streptomycin; EMB, ethambutol; CAP, capreomycin; KAN, kanzmycin; OFX, ofloxacin; MDR, multidrug resistance; XDR, extensively drug resistance. 
Table I Drug susceptibility profiles of 189 clinical Mycobacterium tuberculosis isolates in a tertiary care tuberculosis hospital from China

\begin{tabular}{|c|c|c|c|c|c|c|}
\hline \multirow[t]{2}{*}{ Resistance profiles } & \multicolumn{2}{|c|}{ All patients $(n=189)$} & \multicolumn{2}{|c|}{ New patients $(n=160)$} & \multicolumn{2}{|c|}{ Previously treated patients $(n=29)$} \\
\hline & No. & $\%(95 \% \mathrm{Cl})$ & No. & $\%(95 \% \mathrm{Cl})$ & No. & $\%(95 \% \mathrm{Cl})$ \\
\hline Overall drugs resistance & 54 & $28.6(22.1-35.0)$ & 33 & $20.6(14.4-26.9)$ & 21 & $72.4(56.1-88.7)$ \\
\hline Overall first-line drugs resistance & 53 & $28.0(21.6-34.4)$ & 32 & $20.0(13.8-26.2)$ & 21 & $72.4(56.1-88.7)$ \\
\hline $\mathrm{INH}$ & 42 & $22.2(16.3-28.2)$ & 22 & $13.8(8.4-19.1)$ & 20 & $69.0(52.1-85.8)$ \\
\hline RIF & 19 & $10.1(5.8-14.3)$ & 6 & $3.8(0.8-6.7)$ & 13 & $44.8(26.7-62.9)$ \\
\hline SM & 31 & $16.4(|1|-2 \mid .7)$. & 18 & II.3 (6.4-16.2) & 13 & $44.8(26.7-62.9)$ \\
\hline EMB & 6 & $3.2(0.7-5.8)$ & 2 & $1.3^{\mathrm{a}}$ & 4 & $13.8(1.2-26.3)$ \\
\hline Overall MDR ${ }^{\mathrm{b}}$ & 18 & $9.5(5.3-13.7)$ & 6 & $3.8(0.8-6.7)$ & 12 & $41.4(23.5-59.3)$ \\
\hline $\mathrm{INH}+\mathrm{RIF}$ & 6 & $3.2(0.7-5.8)$ & 3 & $1.9^{\mathrm{a}}$ & 3 & $10.3^{\mathrm{a}}$ \\
\hline $\mathrm{INH}+\mathrm{RIF}+\mathrm{SM}$ & 7 & $3.7(1.0-6.4)$ & 1 & $0.6^{\mathrm{a}}$ & 6 & $20.7(5.9-35.4)$ \\
\hline $\mathrm{INH}+\mathrm{RIF}+\mathrm{EMB}$ & I & $0.5^{\mathrm{a}}$ & I & $0.6^{\mathrm{a}}$ & 0 & $0.0^{\mathrm{a}}$ \\
\hline$I N H+R I F+S M+E M B$ & 4 & $2.1(0.1-0.4)$ & I & $0.6^{\mathrm{a}}$ & 3 & $10.3^{\mathrm{a}}$ \\
\hline Overall second-line drugs resistance & 10 & $5.3(2.1-8.5)$ & 3 & $1.9^{\mathrm{a}}$ & 7 & $24.1(8.6-39.7)$ \\
\hline CAP & 2 & $1.1^{\mathrm{a}}$ & 0 & 0.0 & 2 & $6.9^{\mathrm{a}}$ \\
\hline KAN & 2 & $1.1^{\mathrm{a}}$ & 0 & 0.0 & 2 & $6.9^{\mathrm{a}}$ \\
\hline OFX & 10 & $5.3(2.1-8.5)$ & 3 & $1.9^{\mathrm{a}}$ & 7 & $24.1(8.6-39.7)$ \\
\hline Overall pre-XDR ${ }^{c}$ & 6 & $3.2(0.7-5.8)$ & I & $0.6^{\mathrm{a}}$ & 5 & $8.3^{\mathrm{a}}$ \\
\hline OFX & 6 & $3.2(0.7-5.8)$ & I & $0.6^{\mathrm{a}}$ & 5 & $8.3^{\mathrm{a}}$ \\
\hline Overall XDR ${ }^{d}$ & 2 & $1.1^{\mathrm{a}}$ & 0 & 0.0 & 2 & $6.9^{\mathrm{a}}$ \\
\hline $\mathrm{CAP}+\mathrm{KAN}+\mathrm{OFX}$ & 2 & $1.1^{\mathrm{a}}$ & 0 & 0.0 & 0 & $6.9^{\mathrm{a}}$ \\
\hline
\end{tabular}

Notes: ${ }^{\mathrm{a}} 95 \% \mathrm{Cl}$ was not determined. ${ }^{\mathrm{b}} \mathrm{MDR}$ is defined as resistance to the two first-line drugs, INH and RIF. ${ }^{\mathrm{C}}$ Pre-XDR is defined as TB with resistance to INH and RIF and either OFX or a second-line injectable agent but not both. ${ }^{~} \mathrm{XDR}$ is resistant to INH and RIF, plus OFX and one of the injectable second-line drugs (CAP and KAN).

Abbreviations: $\mathrm{Cl}$, confidence interval; INH, isoniazid; RIF, rifampin; STR, streptomycin; EMB, ethambutol; CAP, capreomycin; KAN, kanzmycin; OFX, ofloxacin; MDR, multidrug resistance; $\mathrm{XDR}$, extensively drug resistance.

Table 2 Factors associated with drug-resistant tuberculosis

\begin{tabular}{|c|c|c|c|c|c|c|c|}
\hline \multirow[t]{2}{*}{ Factors } & \multicolumn{3}{|c|}{ No. (\%) isolates } & \multicolumn{2}{|c|}{$\begin{array}{l}\text { Drug-resistant, but not } \\
\text { MDR-TB vs Pan-suscepti- } \\
\text { ble TB }\end{array}$} & \multicolumn{2}{|c|}{$\begin{array}{l}\text { MDR-TB vs Drug-resis- } \\
\text { tant, but not MDR-TB }\end{array}$} \\
\hline & $\begin{array}{l}\text { Pan-suscepti- } \\
\text { ble TB }\end{array}$ & $\begin{array}{l}\text { drug-resistant, but not } \\
\text { MDR-TB }\end{array}$ & MDR-TB & $\begin{array}{l}\text { Odds Ratio } \\
(95 \% \mathrm{Cl})\end{array}$ & $P$-value & $\begin{array}{l}\text { Odds Ratio } \\
(95 \% \mathrm{CI})\end{array}$ & $P$-value \\
\hline \multicolumn{8}{|l|}{ Sex } \\
\hline Male & 92 & 28 & 12 & reference & & reference & \\
\hline Female & 43 & 8 & 6 & $0.61(0.26-1.46)$ & 0.26 & $1.75(0.50-6.15)$ & 0.58 \\
\hline \multicolumn{8}{|l|}{ Age group } \\
\hline$<30 \mathrm{yr}$ & 52 & 15 & 6 & reference & & reference & \\
\hline $30-59 \mathrm{yr}$ & 60 & 18 & 8 & $1.04(0.48-2.27)$ & 0.92 & I.II (0.32-3.92) & 0.87 \\
\hline$\geq 60 \mathrm{yr}$ & 23 & 3 & 4 & $0.45(0.12-1.72)$ & 0.24 & $3.33(0.57-19.59)$ & 0.21 \\
\hline \multicolumn{8}{|l|}{ Residence area } \\
\hline Urban & 65 & 9 & 6 & reference & & reference & \\
\hline Rural & 70 & 27 & 12 & $2.79(1.22-6.37)$ & $0.0 I^{*}$ & $0.67(0.19-2.30)$ & 0.52 \\
\hline \multicolumn{8}{|l|}{ Sputum smear } \\
\hline positive & 40 & 11 & 9 & reference & & reference & \\
\hline negative & 95 & 25 & 9 & $0.96(0.43-2.13)$ & 0.91 & $0.44(0.14-1.4 I)$ & 0.16 \\
\hline
\end{tabular}

(Continued) 
Table 2 (Continued).

\begin{tabular}{|c|c|c|c|c|c|c|c|}
\hline \multirow[t]{2}{*}{ Factors } & \multicolumn{3}{|c|}{ No. (\%) isolates } & \multicolumn{2}{|c|}{$\begin{array}{l}\text { Drug-resistant, but not } \\
\text { MDR-TB vs Pan-suscepti- } \\
\text { ble TB }\end{array}$} & \multicolumn{2}{|c|}{$\begin{array}{l}\text { MDR-TB vs Drug-resis- } \\
\text { tant, but not MDR-TB }\end{array}$} \\
\hline & $\begin{array}{l}\text { Pan-suscepti- } \\
\text { ble TB }\end{array}$ & $\begin{array}{l}\text { drug-resistant, but not } \\
\text { MDR-TB }\end{array}$ & MDR-TB & $\begin{array}{l}\text { Odds Ratio } \\
(95 \% \mathrm{CI})\end{array}$ & $P$-value & $\begin{array}{l}\text { Odds Ratio } \\
(95 \% \mathrm{CI})\end{array}$ & $P$-value \\
\hline $\begin{array}{l}\text { Treatment } \\
\text { New cases } \\
\text { Previously trea- } \\
\text { ted cases }\end{array}$ & $\begin{array}{l}127 \\
8\end{array}$ & $\begin{array}{l}27 \\
9\end{array}$ & $\begin{array}{l}6 \\
12\end{array}$ & $\begin{array}{l}\text { reference } \\
5.29(1.87-14.96)\end{array}$ & $0.00 * *$ & $\begin{array}{l}\text { reference } \\
6.00(1.74-20.67)\end{array}$ & $0.00 * *$ \\
\hline
\end{tabular}

Notes: $* P<0.05$ (significant); $* * P<0.0$ I (highly significant).

Abbreviation: $\mathrm{Cl}$, confidence interval.

respectively. Moreover, a higher risk of drug resistance (but not MDR) was observed among patients in rural areas with an OR of 2.79 (95\% CI, 1.22-6.37; $P=0.01)$.

\section{Drug susceptibility phenotypes of different genotypes}

The drug-resistant phenotypes of isolates according to different genotypes were summarized in Table 3 . Although most drug resistance occurred in Beijing genotype and modern Beijing genotype strains, statistical analysis revealed that there was no significant difference in the frequencies of drug resistance between different genotypes $(P>0.05)$.

\section{Mutations among drug-resistant isolates}

For drug-resistant isolates, 12 corresponding loci conferring drug resistance were screened. Because synonymous mutations do not lead to amino acid changes, they are unlikely to confer drug resistance. Hence, they were not included in the sequencing results. All nonsynonymous mutations in these loci were summarized in Table 4. In general, mutations in the analyzed hot spot regions were observed in $76.2 \%$ of INH-resistant isolates, $100.0 \%$ of RIF-resistant isolates,

Table 3 the drug resistant profiles of 189 clinical M. tuberculosis isolates of different genotype

\begin{tabular}{|c|c|c|c|c|c|c|}
\hline \multirow[t]{3}{*}{ Resistance } & \multicolumn{4}{|c|}{ Genotype (\%) } & \multicolumn{2}{|l|}{$P$-value } \\
\hline & \multicolumn{3}{|l|}{ Beijng } & \multirow{2}{*}{$\begin{array}{l}\text { Non-Beijing } \\
(n=78)\end{array}$} & \multirow{2}{*}{$\begin{array}{l}\text { Modern vs } \\
\text { Ancient }\end{array}$} & \multirow{2}{*}{$\begin{array}{l}\text { Beijing vs non } \\
\text { Beijing }\end{array}$} \\
\hline & $\begin{array}{l}\text { Total } \\
(n=I I I)\end{array}$ & $\begin{array}{l}\text { Modern } \\
(n=84)\end{array}$ & $\begin{array}{l}\text { Ancient } \\
(n=27)\end{array}$ & & & \\
\hline Overall drugs resistance & $33(29.7)$ & $25(29.8)$ & $8(29.6)$ & $21(26.9)$ & 0.99 & 0.67 \\
\hline $\begin{array}{l}\text { Overall first-line drugs } \\
\text { resistance }\end{array}$ & $32(28.8)$ & $25(29.8)$ & $7(25.9)$ & $21(26.9)$ & 0.70 & 0.77 \\
\hline $\mathrm{INH}$ & $25(29.1)$ & $20(23.8)$ & $5(18.5)$ & $17(2 \mid .8)$ & 0.57 & 0.91 \\
\hline RIF & $12(10.8)$ & $9(10.7)$ & $3(11.1)$ & $7(9.0)$ & 1.00 & 0.68 \\
\hline SM & $20(18.0)$ & $16(19.1)$ & $4(14.8)$ & II (I4.I) & 0.83 & 0.47 \\
\hline EMB & $5(4.5)$ & $4(4.8)$ & I (3.7) & $\mathrm{I}(\mathrm{I} .3)$ & 1.00 & 0.41 \\
\hline overall MDR & $1 \mathrm{I}(9.9)$ & $9(10.7)$ & $2(7.4)$ & $7(9.0)$ & 0.90 & 0.83 \\
\hline $\begin{array}{l}\text { Overall second-line drugs } \\
\text { resistance }\end{array}$ & $9(8.1)$ & $5(6.0)$ & $4(14.8)$ & $\mathrm{I}(\mathrm{I} .3)$ & 0.29 & 0.08 \\
\hline CAP & I (0.9) & $\mathrm{I}(\mathrm{I} .2)$ & $0(0.0)$ & $\mathrm{I}(1.3)$ & 1.00 & 1.00 \\
\hline KAN & I (0.9) & $\mathrm{I}(\mathrm{I} .2)$ & $0(0.0)$ & $\mathrm{I}(\mathrm{I} .3)$ & 1.00 & 1.00 \\
\hline OFX & $9(8.1)$ & $5(6.0)$ & $4(14.8)$ & $\mathrm{I}(\mathrm{I} .3)$ & 0.29 & 0.08 \\
\hline Overall pre-XDR & $5(4.5)$ & $4(4.8)$ & I (3.7) & I (1.3) & 1.00 & 0.41 \\
\hline Overall XDR & I (0.9) & $\mathrm{I}(\mathrm{I} .2)$ & $0(0.0)$ & $\mathrm{I}(\mathrm{I} .3)$ & 1.00 & 1.00 \\
\hline
\end{tabular}


Table 4 Mutations among drug-resistant isolates

\begin{tabular}{|c|c|c|c|c|}
\hline Drug (no. of drug -resistant isolates) & Locus & Mutated position & No. (\%) of isolates & Other mutations \\
\hline \multirow[t]{14}{*}{ INH (42) } & \multirow[t]{5}{*}{ katG } & Gly285Asp & I (2.4) & $C(-10) T$ of oxyR-ahpC \\
\hline & & Ser3I5Ile & I (2.4) & \\
\hline & & Ser3I5Thr & $18(42.9)$ & \\
\hline & & Ser3I5Thr & I (2.4) & $C(-15) T$ of $\operatorname{lnh} A$ \\
\hline & & Thr394Ala & $2(4.8)$ & $C(-15) T$ of $\operatorname{lnh} A$ \\
\hline & \multirow[t]{4}{*}{$\operatorname{inh} A$} & $C(-15) T$ & $6(14.3)$ & \\
\hline & & $C(-15) T$ & I (2.4) & Ser3I5Thr of katG \\
\hline & & $C(-15) T$ & $2(4.8)$ & Thr394Ala of katG \\
\hline & & $C(-15) T$ & I (2.4) & $\mathrm{G}(-5 \mathrm{I}) \mathrm{T}$ of oxyR-ahpC \\
\hline & \multirow{4}{*}{$\begin{array}{l}\text { oxyR-ahpC } \\
\text { intergenic region }\end{array}$} & $\mathrm{G}(-5 \mathrm{I}) \mathrm{T}^{\mathrm{b}}$ & I (2.4) & $C(-15) T$ of $\operatorname{lnh} A$ \\
\hline & & $C(-39) T$ & I (2.4) & \\
\hline & & $C(-15) T$ & I (2.4) & \\
\hline & & $C(-10) T$ & I (2.4) & Gly285Asp of katG \\
\hline & Total $^{\mathrm{a}}$ & & $32(76.2)$ & \\
\hline \multirow[t]{7}{*}{$\operatorname{RIF}(19)$} & \multirow[t]{6}{*}{$r p o B^{c}$} & Asp5I6Val & $2(10.5)$ & \\
\hline & & His526Asp & $3(15.8)$ & \\
\hline & & His526Asn/lle572Leu & I (5.3) & \\
\hline & & His526Ser & I (5.3) & \\
\hline & & Ser53ILeu & II (57.9) & \\
\hline & & Ser53ITrp & I (5.3) & \\
\hline & Total & & $19(100.0)$ & \\
\hline \multirow[t]{6}{*}{ SM (3I) } & \multirow[t]{3}{*}{$r p s L$} & Lys43Arg & $12(38.7)$ & \\
\hline & & Lys88Met & I (3.2) & \\
\hline & & Lys88Arg & $2(6.5)$ & \\
\hline & \multirow[t]{2}{*}{$r r s_{1}$} & $A(5 \mid 4) C$ & $2(6.5)$ & \\
\hline & & $\mathrm{C}(5 \mid 7) \mathrm{T}$ & I (3.2) & \\
\hline & Total & & $18(58.1)$ & \\
\hline \multirow[t]{3}{*}{ EMB (6) } & $\mathrm{embB}$ & Met306Val & $3(50.0)$ & \\
\hline & & Gly406Ala & I (I6.7) & \\
\hline & Total & & $4(66.7)$ & \\
\hline \multirow[t]{2}{*}{ CAP/KAN (2) } & $r r s_{2}$ & $A(I 40 I) G$ & $2(100.0)$ & \\
\hline & Total & & $2(00.0)$ & \\
\hline \multirow[t]{5}{*}{ OFX (I0) } & \multirow[t]{4}{*}{ gryA } & Ala90Val & I $(10.0)$ & \\
\hline & & Ser9IPro & I (10.0) & \\
\hline & & Asp94Ala & $I(10.0)$ & \\
\hline & & Asp94Gly & $5(50.0)$ & \\
\hline & Total & & $8(80.0)$ & \\
\hline
\end{tabular}

Notes: ${ }^{\mathrm{a}}$ Total, all mutated isolates. ${ }^{\mathrm{b}}$ The mutation was not reported previously. ${ }^{\mathrm{C}}$ Amino acid numbers are based on homologous mutations in Escherichia coli.

$58.1 \%$ of SM-resistant isolates, $66.7 \%$ of EMB-resistant isolates, $100.0 \%$ of CAP- or KAN-resistant isolates, and $80.0 \%$ of OFX-resistant isolates. The most common mutations were katG315, rpoB531, rpsL43, embB306, rrs1401, and gyrA94
(Table 4). A novel mutation G(-51)T was observed in $o x y R$ $a h p C$. There was no mutation detected in the sequenced tly $A$, $e i s$, and $g y r B$ loci among the corresponding drug-resistant isolates. 


\section{Discussion}

This study analyzed the epidemiology of drug-resistant TB in a specialized TB hospital of Fujian, China. Most (88.9\%) included patients were Fujian residents. Of them, the proportion of previously treated patients was only $15.3 \%$, significantly lower than the data from other TB hospitals in China. ${ }^{9,16-19}$ This reveals a well functioning local TB control program in Fujian.

The percentage of drug-resistant TB in the study was $28.6 \%$ (54/189 isolates). There was a high rate of drug resistance observed among previously treated patients. Notably, the proportion of drug-resistant TB in previously treated patients (72.4\%) was significantly higher than that found in the national survey (54.5\%). ${ }^{2}$ Different sources of strains would be responsible for this deviation. Strains in the national survey of drugresistant TB were randomly collected from all over China whereas those in this study were obtained from the largest specialized TB hospital in Fujian. Most patients in the hospital who had chronic or refractory TB and had received prior antiTB treatment were more prone to develop drug resistance.

In agreement with other reports, ${ }^{5,8,9}$ previously treated patients in this study were those with the highest risk of developing drug resistance, suggesting that more effective measures must be adopted to increase continuity of treatment and reduce the rate of treatment default. In addition, patients in rural areas demonstrated a higher incidence of drug resistance. One possible reason was that most patients with TB in rural areas received intermittent treatment owing to a lack of money, increasing the possible occurrence of drug-resistant TB.

The proportions of MDR- and XDR-TB in this study were $9.5 \%$ and $1.1 \%$, similar to the data from Shandong, ${ }^{20}$ but lower than data from Beijing, ${ }^{19}$ Guizhou, ${ }^{18}$ Jiangxi, ${ }^{17}$ Hunan, ${ }^{9}$ Shanghai ${ }^{21}$ and Xinjiang. ${ }^{16}$ These findings confirmed that there is a wide variation in drug resistance among regions in China. It is notable that most MDR-TB patients and all XDR-TB patients had a treatment history. This implies that some appropriate strategies must be implemented in the previously treated patients before they develop MDR- and XDR-TB. Furthermore, 33.3\% (6/18) of patients with MDR-TB were pre-XDR TB, placing them only one step away from having XDR-TB.

Although Beijing family was the predominant genotype in this study, its frequency $(58.7 \%)$ was apparently lower than that in other regions of China. ${ }^{17,19,22,23}$ Modern Beijing sublineage was the predominant (75.7\%) Beijing family strain. Some publications have showed that Beijing family strains are associated with drug resistance and greater likelihood of developing MDR-TB. ${ }^{24,25}$ However, other studies and our results suggested that Beijing strains are no more likely to acquire drug resistance than non-Beijing strains. ${ }^{22,26}$

Prior data indicated that drug resistance in TB is often caused by mutations in some genes, especially $k a t G$, inhA and $\operatorname{oxy} R-a h p C, r p o B, r p s L$ and $r r s_{1}, e m b B, t l y A$, eis, $r r s_{2}$, gyr $A$ and gyrB. ${ }^{27-29}$ Thus, we analyzed these genes in the current study. DNA sequencing revealed that the frequency of mutation was $76.2 \%$ in INH-resistant isolates, $100.0 \%$ in RIF-resistant isolates, $66.7 \%$ in EMB-resistant isolates, and $80.0 \%$ in OFX-resistant isolates, consistent with previous reports. ${ }^{7,930,31}$ The mutation frequency in SM-resistant isolates was only $58.1 \%$, lower than in many regions, ${ }^{9,32-34}$ but similar to the rate in another report from Fujian, ${ }^{35}$ revealing that the mutated profiles of SM resistant isolates from different areas might have somewhat regional differences. This result also means that a combination of rps $L$ and rrs for SM resistance in the region could not achieve a satisfactory detection rate. Other genes, such as gidB, should be included for detecting SM resistance. The mutation rate of CAP- or KAN-resistant isolates was $100.0 \%$, significantly higher than the prior data. ${ }^{7,9,15,30}$ Furthermore, no mutation occurred within sequenced tlyA and eis loci, which might be owing to the small number of CAP- or KAN-resistant isolates in this study.

As previously reported, ${ }^{7,9,15,28,35}$ the most prevalent mutations of drug-resistant isolates in this study were katG315, rpoB531, rpsL43, embB306, rrs1401 and gyrA94. Moreover, a novel mutation $\mathrm{G}(-51) \mathrm{T}$, within the $\operatorname{oxy} R-a h p C$ intergenic region, was observed in one $\mathrm{INH}-$ resistant isolate. Although INH-resistant isolates harboring mutations in $\operatorname{oxy} R-a h p C$ are located at various positions between $-74 \mathrm{bp}$ and $-4 \mathrm{bp}$ relative to the start codon of ahpC, mutation at $-51 \mathrm{bp}$ position was very scarce. ${ }^{36} \mathrm{~A}$ single $\mathrm{G}(-51) \mathrm{A}$ mutation was observed in only one $\mathrm{INH}-$ resistant isolate. ${ }^{37}$ This mutation increased expression of the AhpC protein, which could be involved in conferring INH resistance to some TB strains. ${ }^{36,38}$ However, in this study, $\mathrm{G}(-51) \mathrm{T}$ was accompanied by an additional mutation $\mathrm{C}(-15) \mathrm{T}$ in inhA. It was uncertain if this mutation was involved in INH resistance. The actual role of this mutation requires further exploration.

There were several limitations in this study. First, although a substantial number of TB patients were comprised in this research, the number of previously treated patients and patients with drug-resistant TB was relatively small. Next, the drug resistance-associated genes involved in the present study were so limited that some drug 
resistance could not be detected by DNA analysis. In addition, the sequencing data for drug-susceptible isolates were not included in this research, the specificities, accuracy and predictive values of sequencing based assay were not evaluated. Additional studies including a substantial panel of drug-resistant and drug-susceptible isolates will be required in the future.

\section{Conclusion}

The prevalence of INH, RIF, SM, EMB, CAP, KAN and OFX in the tertiary care TB hospital of Fujian was $22.2 \%, 10.1 \%$, $16.4 \%, 3.2 \%, 1.1 \%, 1.1 \%$ and $5.3 \%$, respectively. Modern Beijing sublineage strains constituted the majority of TB. There was no association between drug resistance and genotype. However, previously treated patients and rural patients displayed significantly increased risks of developing drug resistance. DNA sequencing could detect $76.2 \%$ of $\mathrm{INH}$, $100.0 \%$ of RIF, $58.1 \%$ of SM, $66.7 \%$ of EMB, $100.0 \%$ of CAP- or KAN, and $80.0 \%$ of OFX resistance among drugresistant isolates. The most common mutations were kat $G 315$, rpoB531, rpsL43, embB306, rrs 1401, and gyrA94. These findings will be useful in designing appropriate TB control strategies, which will be applied in this region and then throughout China.

\section{Acknowledgments}

We thank the staff of Fujian for supplying strains. This study was supported by the projects from National Key Program of Mega Infectious Diseases (Grant No. 2018ZX10302302001) and National Basic Research Program of China (973 Program, Grant No. 2015CB554202). The funder had no role in the study design, data collection and analysis, decision to publish, or manuscript preparation.

\section{Disclosure}

The authors report no conflicts of interest in this work.

\section{References}

1. World Health Organization. Global tuberculosis report 2014. WHO/HTM/ TB/2014.8. Geneva (Switzerland): World Health Organization: 2014.

2. Zhao Y, Xu S, Wang L, et al. National survey of drug-resistant tuberculosis in China. $N$ Engl $J$ Med. 2012;366(23):2161-2170. doi:10.1056/NEJMoa1108789

3. Gandhi NR, Nunn P, Dheda K, et al. Multidrug-resistant and extensively drug-resistant tuberculosis: a threat to global control of tuberculosis. Lancet. 2010;375(9728):1830-1843. doi:10.1016/S0140-6736(10)60410-2

4. Afanas'ev MV, Ikryannikova LN, Il'ina EN, et al. Molecular characteristics of rifampicin- and isoniazid-resistant Mycobacterium tuberculosis isolates from the Russian Federation. J Antimicrob Chemother. 2007;59(6):1057-1064. doi:10.1093/jac/dkm086
5. He GX, Zhao YL, Jiang GL, et al. Prevalence of tuberculosis drug resistance in 10 provinces of China. BMC Infect Dis. 2008;8:166. doi:10.1186/1471-2334-8-166

6. Ramazanzadeh R, Farnia P, Amirmozafari N, et al. Comparison between molecular epidemiology, geographical regions and drug resistance in Mycobacterium tuberculosis strains isolated from Iranian and Afghan patients. Chemotherapy. 2006;52(6):316-320. doi:10.1159/000095971

7. Zhao LL, Chen Y, Liu HC, et al. Molecular characterization of multidrug-resistant Mycobacterium tuberculosis isolates from China. Antimicrob Agents Chemother. 2014;58(4):1997-2005. doi:10.1128/AAC.01792-13

8. Zignol M, Wright A, Jaramillo E, Nunn P, Raviglione MC. Patients with previously treated tuberculosis no longer neglected. Clin Infect Dis. 2007;44(1):61-64. doi:10.1086/509328

9. Zhao LL, Chen Y, Chen ZN, et al. Prevalence and molecular characteristics of drug-resistant Mycobacterium tuberculosis in Hunan, China. Antimicrob Agents Chemother. 2014;58(6):3475-3480. doi:10.1128/AAC.02426-14

10. WHO. Policy guidance on TB drug susceptibility testing (DST) of second-line drugs. WHO/HTM/TB/2008392. Geneva (Switzerland): WHO; 2008.

11. Guidelines for surveillance of drug resistance in tuberculosis. WHO Geneva/IUATLD Paris. International Union Against Tuberculosis and Lung Disease. Int J Tuberc Lung Dis. 1998;2(1):72-89.

12. Somerville W, Thibert L, Schwartzman K, Behr MA. Extraction of Mycobacterium tuberculosis DNA: a question of containment. J Clin Microbiol. 2005;43(6):2996-2997. doi:10.1128/JCM.43.6.2996-2997. 2005

13. Kamerbeek J, Schouls L, Kolk A, et al. Simultaneous detection and strain differentiation of Mycobacterium tuberculosis for diagnosis and epidemiology. J Clin Microbiol. 1997;35(4):907-914.

14. Wada T, Iwamoto T, Maeda S. Genetic diversity of the Mycobacterium tuberculosis Beijing family in East Asia revealed through refined population structure analysis. FEMS Microbiol Lett. 2009;291(1):35-43. doi:10.1111/j.1574-6968.2008.01431.x

15. Zhao LL, Sun Q, Zeng CY, et al. Molecular characterisation of extensively drug-resistant Mycobacterium tuberculosis isolates in China. Int J Antimicrob Agents. 2015;45(2):137-143. doi:10.1016/j. ijantimicag.2014.09.018

16. Qi YC, Ma MJ, Li DJ, et al. Multidrug-resistant and extensively drug-resistant tuberculosis in multi-ethnic region, Xinjiang Uygur Autonomous Region, China. PLoS One. 2012;7(2):e32103. doi:10.1371/journal.pone.0032103

17. Yuan X, Zhang T, Kawakami K, et al. Genotyping and clinical characteristics of multidrug and extensively drug-resistant tuberculosis in a tertiary care tuberculosis hospital in China. BMC Infect Dis. 2013;13:315. doi:10.1186/1471-2334-13-315

18. Lan Y, Li Y, Chen L, Zhang J, Zhang H. Drug resistance profiles and trends in drug-resistant tuberculosis at a major hospital in Guizhou Province of China. Infect Drug Resist. 2019;12:211-219. doi:10.2147/IDR.S188538

19. Liu Y, Jiang X, Li W, Zhang X, Wang W, Li C. The study on the association between Beijing genotype family and drug susceptibility phenotypes of Mycobacterium tuberculosis in Beijing. Sci Rep. 2017;7(1):15076. doi:10.1038/s41598-017-14119-z

20. Deng Y, Wang Y, Wang J, et al. Laboratory-based surveillance of extensively drug-resistant tuberculosis, China. Emerg Infect Dis. 2011;17(3):495-497. doi:10.3201/eid1703.100812

21. Tang S, Zhang Q, Yu J, et al. Extensively drug-resistant tuberculosis, China. Emerg Infect Dis. 2011;17(3):558-560. doi:10.3201/ eid1703.100919

22. Wang J, Liu Y, Zhang CL, et al. Genotypes and characteristics of clustering and drug susceptibility of Mycobacterium tuberculosis isolates collected in Heilongjiang Province, China. $J$ Clin Microbiol. 2011;49(4):1354-1362. doi:10.1128/JCM.02274-10 
23. Liu Q, Yang D, Xu W, et al. Molecular typing of Mycobacterium tuberculosis isolates circulating in Jiangsu province, China. BMC Infect Dis. 2011;11:288. doi:10.1186/1471-2334-11-208

24. Tanveer M, Hasan Z, Siddiqui AR, et al. Genotyping and drug resistance patterns of $\mathrm{M}$. tuberculosis strains in Pakistan. BMC Infect Dis. 2008;8:171. doi:10.1186/1471-2334-8-171

25. Ghebremichael S, Groenheit R, Pennhag A, et al. Drug resistant Mycobacterium tuberculosis of the Beijing genotype does not spread in Sweden. PLoS One. 2010;5(5):e10893. doi:10.1371/journal. pone.0010893

26. Alonso M, Alonso Rodriguez N, Garzelli C, et al. Characterization of Mycobacterium tuberculosis Beijing isolates from the Mediterranean area. BMC Microbiol. 2010;10:151. doi:10.1186/ 1471-2180-10-151

27. Islam MM, Hameed HMA, Mugweru J, et al. Drug resistance mechanisms and novel drug targets for tuberculosis therapy. $J$ Genet Genomics. 2017;44(1):21-37. doi:10.1016/j.jgg.2016.10.002

28. Campbell PJ, Morlock GP, Sikes RD, et al. Molecular detection of mutations associated with first- and second-line drug resistance compared with conventional drug susceptibility testing of Mycobacterium tuberculosis. Antimicrob Agents Chemother. 2011;55(5):2032-2041. doi:10.1128/AAC.01550-10

29. Wade MM, Zhang Y. Mechanisms of drug resistance in Mycobacterium tuberculosis. Front Biosci. 2004;9:975-994.

30. Yuan X, Zhang T, Kawakami K, et al. Molecular characterization of multidrug- and extensively drug-resistant Mycobacterium tuberculosis strains in Jiangxi, China. J Clin Microbiol. 2012;50(7):24042413. doi:10.1128/JCM.06860-11

31. Zhang Z, Lu J, Liu M, et al. Genotyping and molecular characteristics of multidrug-resistant Mycobacterium tuberculosis isolates from China. $J$ Infect. 2015;70(4):335-345. doi:10.1016/j.jinf.2014.11.008
32. Zhao LL, Liu HC, Sun Q, et al. Identification of mutations conferring streptomycin resistance in multidrug-resistant tuberculosis of China. Diagn Microbiol Infect Dis. 2015;83(2):150-153. doi:10.1016/j. diagmicrobio.2015.06.020

33. Sun H, Zhang C, Xiang L, et al. Characterization of mutations in streptomycin-resistant Mycobacterium tuberculosis isolates in Sichuan, China and the association between Beijing-lineage and dual-mutation in gidB. Tuberculosis. 2016;96:102-106. doi:10.1016/ j.tube.2015.09.004

34. Shi R, Zhang J, Li C, Kazumi Y, Sugawara I. Detection of streptomycin resistance in Mycobacterium tuberculosis clinical isolates from China as determined by denaturing HPLC analysis and DNA sequencing. Microbes Infect. 2007;9(14-15):1538-1544. doi:10. 1016/j.micinf.2007.08.009

35. Chen Q, Pang Y, Liang Q, et al. Molecular characteristics of MDR Mycobacterium tuberculosis strains isolated in Fujian, China. Tuberculosis. 2014;94(2):159-161. doi:10.1016/j.tube. 2013.03.004

36. Unissa AN, Subbian S, Hanna LE, Selvakumar N. Overview on mechanisms of isoniazid action and resistance in Mycobacterium tuberculosis. Infect Genet Evol. 2016;45:474-492. doi:10.1016/j. meegid.2016.09.004

37. Rinder H, Thomschke A, Rusch-Gerdes S, et al. Significance of ahpC promoter mutations for the prediction of isoniazid resistance in Mycobacterium tuberculosis. Eur J Clin Microbiol Infect Dis. 1998;17(7):508-511

38. Slayden RA, Barry CE 3rd. The genetics and biochemistry of isoniazid resistance in mycobacterium tuberculosis. Microbes Infect. 2000;2(6):659-669. doi:10.1016/S1286-4579 (00)00359-2
Infection and Drug Resistance

\section{Publish your work in this journal}

Infection and Drug Resistance is an international, peer-reviewed openaccess journal that focuses on the optimal treatment of infection (bacterial, fungal and viral) and the development and institution of preventive strategies to minimize the development and spread of resistance. The journal is specifically concerned with the epidemiology of antibiotic resistance and the mechanisms of resistance development and diffusion in both hospitals and the community. The manuscript management system is completely online and includes a very quick and fair peerreview system, which is all easy to use. Visit http://www.dovepress.com/ testimonials.php to read real quotes from published authors. 